\title{
The acceptability to women of techniques for managing an impacted fetal head at caesarean section and of randomised trials evaluating those techniques: a qualitative study
}

Gabriella Romano ${ }^{1}$, Eleanor Mitchell ${ }^{2}$, Rachel Plachcinski ${ }^{3}$, Natalie Wakefield ${ }^{2}$, Kate Walker ${ }^{2,4^{*}}$ (i) and Susan Ayers ${ }^{1}$

\begin{abstract}
Background: This study aimed to explore women's views on the acceptability of different techniques for managing an impacted fetal head at caesarean; and the feasibility and acceptability of conducting a trial in this area.

Methods: Qualitative semi-structured interviews with a systematic sample of women who experienced second stage emergency caesarean section at a tertiary National Health Service (NHS) hospital in England, UK. Thematic analysis was used to extract women's views.

Results: Women varied in their perceptions of the acceptability of different techniques for managing impacted fetal head. Trust in medical expertise and prioritising the safety of the baby were important contextual factors. Greater consensus was found around informed choice in trials where subthemes considered the timing of invitation, reduced capacity to give consent in emergency situations, and the importance of birth outcomes and having good rapport with healthcare professionals who invite women into trials. Finally, women reflected on the importance of supportive antenatal and postpartum education for impacted fetal head.
\end{abstract}

Conclusions: This research provides information on the acceptability of techniques and any trial to evaluate these techniques. Findings illustrate the importance of context and quality of care to both acceptability and approaching women to take part in a future trial.

Keywords: Feasibility, Acceptability, Caesarean, Techniques for impacted fetal head, Qualitative

\footnotetext{
* Correspondence: Kate.Walker@nottingham.ac.uk

${ }^{2}$ Nottingham Clinical Trials Unit, University of Nottingham, Building 42 University Park, Nottingham NG7 2RD, UK

${ }^{4}$ Division of Child Health, Obstetrics and Gynaecology, School of Medicine, Lenton, University of Nottingham, Nottingham NG7 2RD, UK

Full list of author information is available at the end of the article
}

(c) The Author(s). 2021 Open Access This article is licensed under a Creative Commons Attribution 4.0 International License, which permits use, sharing, adaptation, distribution and reproduction in any medium or format, as long as you give appropriate credit to the original author(s) and the source, provide a link to the Creative Commons licence, and indicate if changes were made. The images or other third party material in this article are included in the article's Creative Commons licence, unless indicated otherwise in a credit line to the material. If material is not included in the article's Creative Commons licence and your intended use is not permitted by statutory regulation or exceeds the permitted use, you will need to obtain permission directly from the copyright holder. To view a copy of this licence, visit http://creativecommons.org/licenses/by/4.0/. The Creative Commons Public Domain Dedication waiver (http://creativecommons.org/publicdomain/zero/1.0/) applies to the data made available in this article, unless otherwise stated in a credit line to the data. 


\section{Background}

Emergency caesarean section (CS) accounts for 16\% of all births in the UK [1] of which at least 5\% are done at full dilatation in the second stage of labour, that is 4830 births per annum [2]. Emergency CS performed in the second stage of labour has greater perinatal and maternal morbidity than those performed in the first stage [3]. Second stage CS may be complicated by the fetal head being deeply impacted in the maternal pelvis which occurs in $1.5 \%$ of all emergency CS $[3,4]$. As an obstetric emergency, the challenge for the clinical team is to disengage the head by hand due to minimal space between the bony maternal pelvis and the deeply impacted fetal head. Complications can arise for mother and baby and include: major haemorrhage secondary to uterine or vaginal tears, longer hospital stay and delivery times, greater risk of bladder trauma, injury to the baby [3] such as bony fractures, hypoxic brain injury or occasionally death.

There is currently no UK or international guidance on which techniques to employ to manage an impacted fetal head at CS. Numerous techniques to assist in delivery of an impacted head are reported but the superiority of one technique over another is contentious [5]. Most commonly used techniques include: the reverse breech or 'pull technique', the 'push technique', and fetal pillow [6]. A review of randomised controlled trials (RCTs) of different techniques concluded there is insufficient evidence to support or refute the use of any technique to facilitate infant birth during a difficult caesarean section [5]. In the UK, obstetricians and midwives do not receive standardised training. Thus, there is no consensus on best practice and research is needed to inform the methods used by clinical teams during these critical incidents and determine which is the most effective.

The objective of this research was to qualitatively examine women's views on the acceptability of different techniques for managing an impacted fetal head during emergency CS; and the feasibility and acceptability of conducting a RCT in this area. The Medical Research Council framework [7] provides guidance on the development and evaluation of complex interventions [8]. A range of methods can be used to examine feasibility, with qualitative studies increasingly incorporated prior to or during RCTs to assess acceptability and feasibility. This qualitative study is part of a larger programme of work, including national surveys of current practice and parents' views, and a Delphi study to agree which techniques should be tested. This will provide valuable information needed to determine whether it is possible to conduct an RCT in this area.

\section{Methods}

\section{Sample and recruitment}

A systematic sample of women was recruited through one hospital in England. Women were eligible if they had experienced a second stage CS in the 24 months prior to recruitment; were aged 16 years or older; had adequate spoken English; and were able to give informed consent. There were no exclusion criteria. All women who were eligible over a 24 -month period $(n=140)$ were identified from medical records. Of these, 80 were invited to participate: 50 who lived in deprived areas (i.e. an Index of Multiple Deprivation Decile (IMD) of 1 or 2 ) and 30 in less deprived areas (IMD of 3-10). Women who were interested in taking part returned a pre-paid letter to the research team providing contact details and a signed consent form. Postal responses were returned by 19 women interested in taking part: 17 consented and 2 expressed interest but did not return the consent form. Of women who consented, 9 (53\%) were available to be interviewed. The remaning 8 women were not available to be interviewed during the study period.

Women were offered an initial telephone call with a research psychologist so they could ask questions and state their preference for a one-to-one interview or focus group. Nearly all women preferred one-to-one interviews. Interviews were conducted at the university campus by two practitioners: a psychologist experienced in qualitative research with vulnerable groups, and a $\mathrm{Na}$ tional Childbirth Trust practitioner experienced in explaining birth-related information in an accessible way. Women were able to bring their baby to the interview and were reimbursed for travel and childcare costs.

Before the interview participants provided sociodemographic information and were given brief information about the study and the different techniques used for impacted fetal head. Participants were shown photos and physical prototypes of the fetal pillow and Tydeman tube instruments during the presentation. A 45-min semistructured interview was then conducted to explore participants' experiences and views on the acceptability of different techniques and a RCT of techniques using a topic guide. This interview guide was developed for this study and is provided as an Appendix (S1). Not all women were aware of whether or not they had experienced an impacted head. Women were shown photographs and diagrams to illustrate the different techniques and where appropriate were shown a real life version (fetal pillow; Tydeman Tube) that they could handle themselves. A model pelvis and baby were also used to explain the different techniques.

If women wanted additional information about their birth and/or referral to an obstetrician to find out more they were encouraged to contact their GP. Information was given in the Participant Information Sheet for 
recommendations of who they could contact. The number of interviews conducted was dependent on women's availability. All interviews were audio recorded and transcribed using an external transcription agency.

\section{Data analysis}

Audio recordings were transcribed verbatim and analysed using systematic thematic analysis [9]. A combined inductive and deductive approach was used with the following steps: first, all transcripts were read to become familiar with the data. Transcripts were then re-read and initial codes identified and coded. When no further codes emerged (i.e. data saturation) all the codes were examined by two researchers (GR and SA) to agree which were most frequent or could be combined into key themes. Themes were cross-checked against coded quotes to ensure reliability of coding and that main themes were represented. Analysis was conducted using NVivo12 software [10].

\section{Results}

\section{Sample characteristics}

Participants were 30-40 years of age and all White British. Five participants were married and the remainder $(n=4)$ were living with their partner. The majority of women were educated to degree level $(n=5)$ or above $(n=1)$. All participants were in employment across a range of industries including healthcare $(n=3)$, retail $(n=3)$, probation $(n=1)$, education $(n=1)$ and catering $(n=1)$.

\section{Main themes}

Three main themes were identified: (1) Acceptability of different techniques; (2) Informed choice in trials; and (3) Birth education. Each theme had a number of subthemes as shown in Table 1.

\section{Theme 1: Acceptability of different techniques}

The acceptability of different techniques varied between women. This is illustrated in Table 2 which summarises the contrasting choices of techniques that different women preferred. Variation in acceptability of different techniques appeared to be due to three key subthemes: Level of invasiveness, Security in practitioner expertise and Baby safety.

Level of invasiveness When weighing up the acceptability of one technique over another, women often talked about the extent to which an approach was invasive or intrusive to them or the baby. Women differed in what they perceived as intrusive, be it a clinician's hand, instrument or a physical approach.

.. you want the least intrusive thing that you can get hold of, really. And they don't seem as bad as some of the alternatives ... like, the head down tilt thing seems less invasive than some of the ones where you'd be using instruments, and that sort of thing. (P5)

Another participant described a sense of safety of the doctor's hand as it is viewed as something that has a high level of sensitivity and functionality compared with a tool or inanimate object.

So erm yeah ..., perhaps it's safer to actually have somebody doing that, with their own hand, rather than a plastic implement (P7)

Invasiveness was also understood in terms of potential risk of infection. This participant talks about the importance of hygiene.

I suppose I prefer the tube or the pillow rather than the midwife hands I think ... they just seem a bit more hygienic and a bit more cleaner (P8)

Table 1 Themes and subthemes

\begin{tabular}{|c|c|c|}
\hline Themes & Subthemes & $\begin{array}{l}\text { Participants } \\
\text { N (\%) }\end{array}$ \\
\hline \multirow[t]{3}{*}{ Acceptability of different techniques } & Level of invasiveness & $5(55 \%)$ \\
\hline & Security in practitioner expertise & $5(55 \%)$ \\
\hline & Baby safety & $4(44 \%)$ \\
\hline \multirow[t]{4}{*}{ Informed choice in trials } & Timing of invitation & $7(77 \%)$ \\
\hline & Capacity to make an informed choice & $5(55 \%)$ \\
\hline & Birth outcome & $3(33 \%)$ \\
\hline & Importance of rapport & $4(44 \%)$ \\
\hline \multirow[t]{2}{*}{ Birth education } & Antenatal education & $9(100 \%)$ \\
\hline & Postpartum information & $7(77 \%)$ \\
\hline
\end{tabular}


Table 2 Summary of women's views on which technique(s) they preferred

\begin{tabular}{|c|c|}
\hline Techniques & Justification for choice \\
\hline $\begin{array}{l}\text { Head down or the push } \\
\text { technique }\end{array}$ & $\begin{array}{l}\text {... probably the ones where the pushing and the head down tilt one, feels a bit more natural, I would say .... cos it feels } \\
\text { like you're, for the way you described it, unless I have misunderstood it, it feels like me, as the mother who's trying to give } \\
\text { birth to my child, I still am trying to give birth to my child with some more assistance. Whereas, these feel completely, the } \\
\text { power's more out of my hands a little bit. Yeah. (P1) }\end{array}$ \\
\hline Tydeman tube & $\begin{array}{l}\text {... I prefer the tube because the doctor would be holding on to the bottom ... and the air as well, will release a suction, so } \\
\text { cos that will have a benefit over just using your hand because they'll be able to get rid of the suction with the air ... the } \\
\text { hand you have better control ... (P2) }\end{array}$ \\
\hline Fetal pillow & $\begin{array}{l}\text { I suppose this one [pillow] would be better than that [tube]. ...this pillow it seems, it looks erm, I don't know about the right } \\
\text { word, don't look as hard as the tube... I think to be pushing on a baby's soft skull. I think they've had enough sort of } \\
\text { trauma down there already and the head's getting squashed. And then to be coming from that way pushing them up ... } \\
\text { but maybe the pillow feels like a soft sort of 'fabric'. (P3) }\end{array}$ \\
\hline \multirow[t]{3}{*}{$\begin{array}{l}\text { Tydeman tube or the Fetal } \\
\text { pillow }\end{array}$} & $\begin{array}{l}\text { Any of those techniques would be preferable to having hands or really physically pulling on a baby ... I think sometimes } \\
\text { you can feel like you are being manhandled I think and people can be a bit rough (P4) }\end{array}$ \\
\hline & $\begin{array}{l}\text { Um, possibly the pillow and the tube, maybe. I think the, I don't know how to pronounce it, Patwardhan Method, is the } \\
\text { furthest method away. That really seems like a very, very, within an emergency, an extra emergency kind of procedure to } \\
\text { me. (P5) }\end{array}$ \\
\hline & $\begin{array}{l}\text {... if I had a choice in terms of how, if that technique was gonna be used, I'd rather something like this, it would be slightly } \\
\text { more gentle... than the other, like the push technique (P6) }\end{array}$ \\
\hline $\begin{array}{l}\text { Health professionals' } \\
\text { decision }\end{array}$ & $\begin{array}{l}\text { None of them seem particularly unacceptable or you know, there was nothing that I thought, oh, I really wouldn't want to } \\
\text { have that done to me..... I would put my hand in the health professional to be choosing the right implement ... cos } \\
\text { you don't really have a choice anyway. (P7) }\end{array}$ \\
\hline \multirow[t]{2}{*}{ Any technique } & $\begin{array}{l}\text { I suppose I would be happy with whatever you had to use really. I suppose you trust the doctor to make the right decision } \\
\text { don't you and whatever you need to do to make sure the baby is safe really. (P8) }\end{array}$ \\
\hline & $\begin{array}{l}\text { I would go with anything. I'm quite trusting of medicine, and if something has to be done then that's what has to be done, } \\
\text { you know. (P9) }\end{array}$ \\
\hline
\end{tabular}

Security in practitioner expertise Some women talked about trusting the medical team to use the appropriate technique.

I suppose I would be happy with whatever you had to use really. I suppose you trust the doctor to make the right decision don't you and whatever you need to do to make sure the baby is safe really. (P8)

A few women mentioned that the technique used was less important than ensuring women feel secure and reassured by the clinical team during the emergency situation.

I think it's, that it is really important in terms of making sure mum's emotional wellbeing is you know at the forefront in terms of.. 'cos you've got to perform this surgery, it's huge surgery, you need to make sure that she feels secure in your care so that actually when she leaves there she's like okay (laughs) well that's happened (P6).

Baby safety Lastly the extent to which a technique may damage or threaten the safety of their baby was mentioned by some women when considering acceptability.

The other things ... . Tocolysis, I'm not sure, I would probably put that as more, last resort if, obviously the main thing is to save the baby, so I would do anything if the baby was in trouble (P2)

Another participant emphasised the importance of the baby arriving safely and less concerned about if it is damaged during the process.

Even if it meant to deliver your baby we had to break the baby's leg, it sounds horrific but I personally, would much rather that than not have a baby.

\section{Theme 2: informed choice in trials}

Women's views of a trial of different techniques produced the theme Informed choice in trials which had four subthemes of: Timing of the invitation, Capacity to make an informed choice, Birth outcome and Importance of rapport.

Timing of the invitation Timing of an invitation to take part in a trial was important, as being offered information before birth would allow women time to understand and reflect on the project.

I think it's quite a stressful time anyway, and there is quite a lot going on. ... ... if you are asked earlier on in the process, then you have got more time to sort of think about it properly, if that makes sense 
and ... give a ... sort of more informed right choice

(P8)

Capacity to make an informed choice There was a consistent view from women that under critical conditions consenting to a trial would be challenging. Furthermore, in an emergency situation they might be more compliant and agree to anything, therein not being able to consider information thoughtfully.

I appreciate all of that and I'd have been more than happy to be part of it, as I am now, but I just think you can't ask people at those times. I just don't know if they have full capacity even ... I just wasn't even thinking right ... (P3)

Birth outcome Women described a willingness to take part in research once they were confident their baby was safe and well.

After the baby's nicely, safely delivered, so that would be, I'd of said yes to anything when my baby was here safely (P4)

After the baby has been ... yeah that probably will be better, yeah because yeah you are sort of almost ... you have gone through the process and you are relieved that everything is okay. (P8)

Importance of rapport Lastly, participants described the importance of being approached for research purposes by a clinician they knew; most women identified their midwife.

I think maybe more by a midwife than anybody else ... cos you have that, you have more of a relationship with your midwife than anybody else (P4)

\section{Theme 3: Birth education}

Women spontaneously reflected on their own birth experience and what would have been helpful in hindsight. The theme Birth education emerged from women reflecting on their experiences of having a second stage emergency CS and the need for education and knowledge before and after. This had two subthemes of Antenatal education and Postpartum information.

Antenatal education Antenatal education and knowledge were seen as an opportunity to have some control over the impact of birth events as opposed to being blind to potential adverse events.
Going into a situation you know nothing about it takes away a lot of your control I think ... you wouldn't do this for any other surgery, you wouldn't approach any other situation without the full picture, but you present women who are pregnant with this almost glorified text book (P4)

Participants reflected on whether it's important for women to be informed about all types of birth outcomes, not just positive 'glorified' births. Women raised the importance of reframing narratives around CS at antenatal classes as like any other type of birth in order to minimise a sense of failure among women who have a CS.

So actually I think there probably is a lot more education that could be available so people ... don't feel this is a weird way to give birth, but it's still a way to give birth (P4)

Postpartum information Similarly, women raised the importance of information postpartum to understand events during birth. Women discussed the value of processing the events of birth afterwards. They discussed the value of knowledge in validating their experiences and alleviating the negative emotional impact.

... . Because I had to stay in hospital for five days afterwards. Um, and he just came back and sort of said, "Do you know what's happened to you?" (Laughs). And I said (High voice), "Ooh no, I don't think I do." (Laughs). I was very emotional. And then he explained it all to me, and that actually made me feel 1,000 times better, just him taking five minutes just to explain that to me (P1)

\section{Discussion}

Main findings

This study aimed to determine the acceptability of different techniques for managing impacted fetal head at CS; and the feasibility and acceptability to women of conducting an RCT of those techniques. Women varied in which technique they thought was most acceptable. Women's trust in medical expertise and prioritising the safety of the baby were important moderators of acceptability of techniques. Greater consensus was found on factors important to consider in a future RCT. These included timing of consent, capacity to consent in emergency situations, the importance of birth outcomes, and good rapport with the consenting clinicians. Women also reflected on antenatal education and postpartum information being important when complications like impacted fetal head arise. 


\section{Strengths and limitations}

This research is the first to examine the acceptability to women of different techniques to manage impacted fetal head and their views on a possible RCT to evaluate techniques. Limitations of the study are that the sample was small and included a high proportion of women educated to degree level or above, most women were working and, incidentally, a third of these women worked in healthcare. All women were White British. The sample is therefore not representative and the results not generalisable. The consistency of our findings with previous literature suggests some elements may be generalisable but further research is needed to look at the acceptability of techniques to manage impacted fetal head in women from other socio-economic and ethnic groups. As women were interviewed up to 2 years after their CS it is possible there is an element of recall bias in their responses, although research suggests women have accurate recall of birth events 4-6 years postpartum [11].

\section{Interpretation}

This study did not identify one technique that would be acceptable to all women. Preferred techniques included: fetal pillow, Tydeman tube, head down tilt and push technique. No woman chose reverse breech extraction, tocolysis or Padwardhan technique. These views are consistent with previous research: a meta-review of 43 reviews of acceptability of healthcare interventions highlighted that acceptability is a multifaceted construct which involves individual's thoughts, feelings and behaviour, and can be individually and/or socially acceptable to patients or health professionals [12]. Acceptability can be prospective based on anticipated responses, or retrospective, based on experience [12]. The acceptability of an intervention is also likely to vary according to the content, context and quality of care [12]. This is consistent with our findings that trust in medical expertise and prioritising the safety of the baby in emergency situations influenced acceptability of techniques.

This has a number of implications. First, our participants reported acceptability in relation to anticipated responses, not known past experience. However, participants had all experienced second stage CS so the interviews sometimes prompted the realisation that they may have experienced impacted fetal head and one of these techniques may have been used without them knowing which one. Results in relation to acceptability are therefore not based on known experience of different techniques, but were conducted with women who had been in similar, or closely related, circumstances. Second, the importance of context and quality of care is evident across all themes, especially in subthemes of Baby safety, Birth outcome, Security in practitioner expertise and Importance of rapport. Similarly, it could be argued that the theme of Education is predominantly about context (i.e. women's knowledge) and care (i.e. antenatal and postnatal education and information).

Findings about acceptability of a trial are consistent with literature on trials of procedures in emergency situations. Findings about the importance of informed choice are consistent with guidelines that emphasise informed consent for research must include capacity, disclosure, understanding, voluntariness and permission [13]. The difficulty obtaining informed consent in emergency or critical situations has been widely debated. Although women in this study wanted information beforehand in order to consider it, the advantages and disadvantages of this are recognised in guidelines for obstetric research [14]. In some circumstances informing women in advance might create unnecessary anxiety, particularly if the obstetric complication is rare [14]. On the other hand, trying to obtain consent during critical situations may delay life-saving treatment and if women are under stress they may lack capacity to give fully informed consent [15].

Different proposals for gaining consent in emergency circumstances have been proposed, including deferred consent (requested after the emergency and procedure) [16], or a two-stage process of verbal consent during the emergency followed by written consent after the event [17]. A qualitative study of women's experiences of consent during or after birth (i.e. deferred consent) found that women's experiences of trial participation were the same regardless of the way in which they gave consent. The authors concluded clinicians' understanding of a woman's individual situation and experience is paramount in negotiating consent during obstetric emergencies [16].

Thus, context and quality of care is important in both acceptability of interventions to women as well as consent procedures. This is consistent with our findings that women wanted to feel security in practitioner expertise and emphasised the importance of rapport with the clinician who invited them to take part in a trial. Similarly, safety of the baby was mentioned in relation to acceptability of techniques to manage impacted fetal head (baby safety) and in relation to obtaining consent (birth outcomes).

The theme of Birth education and information emerged spontaneously. Women thought antenatal education could have prepared them better for their birth experiences, and that postpartum information was helpful. It is increasingly recognised that some women find birth traumatic and complications such as emergency CS are a risk factor [18]. Although it should be noted that women's subjective birth experience is more strongly associated with traumatic stress reactions to birth [19]. 


\section{Conclusion}

Results offer insights for health professionals working with emergency obstetric procedures such as impacted fetal head. Findings highlight the individual variability in the acceptability of techniques for managing impacted fetal head to different women, as well as the importance of context and quality of care. In approaching women to take part in a future trial, flexibility of approaches is required. Ideally women would have time to consider and consent before the critical situation arises but, if not, full written consent should not be sought in critical or emergency situations when women have limited capacity. Ideally, women should be approached by a healthcare professional known to them.

Further research is needed to consider acceptability in different groups of women, such as those from different socio-economic and ethnic backgrounds, as well as women who have experienced impacted fetal head and one of the techniques. Acceptability of techniques to healthcare professionals expected to use these techniques in a future trial is also important to examine in conjunction with women's views.

\section{Supplementary Information}

The online version contains supplementary material available at https://doi. org/10.1186/s12884-021-03577-z

\section{Additional file 1.}

\section{Abbreviations}

CS: Caesarean Section; RCT: Randomized Controlled Trial; IMD: Index of Multiple Deprivation Decile

\section{Acknowledgements}

The research team would like to thank the women who volunteered their time to participate in interviews. Your insights and experiences will inform future practice among health professions working in this field. We would also like to thank Lesley Hodgen, research midwife at Nottingham University Hospitals NHS Trust for her help identifying research participants, and Nazihah Uddin at City, University of London for her help preparing the manuscript.

\section{Authors' contributions}

KW, SA and EM were responsible for the conception of the study and planning delivery. NW was responsible for planning and coordinating recruitment and participant expense compensation. RP and GR were responsible for conducting interviews. GR was responsible for liaising with recruited participants, analysis of the transcripts and drafting the manuscript. All authors read and approved the final manuscript.

\section{Funding}

This project is funded by the National Institute for Health Research (NIHR) Health Technology Assessment programme (project reference 17/75/09). The views expressed are those of the author(s) and not necessarily those of the NIHR or the Department of Health and Social Care. The funding body approved the final design of the study. The funding body had no involvement in the collection, analysis, and interpretation of data and in writing the manuscript.

\section{Availability of data and materials}

The dataset supporting the conclusions of this article is available from the corresponding author on request.

\section{Ethics approval and consent to participate}

Ethical approval was obtained from the West Midlands, Solihull, Research Ethics Committee (REC 19/WM/0118). All participants in the study gave their written consent.

\section{Consent for publication}

Not applicable.

\section{Competing interests}

The authors declare that they have no competing interests.

\section{Author details}

${ }^{1}$ Centre for Maternal and Child Health Research, School of Health Sciences, City, University of London, Northampton Square, London EC1V OHB, UK. ${ }^{2}$ Nottingham Clinical Trials Unit, University of Nottingham, Building 42 University Park, Nottingham NG7 2RD, UK. ${ }^{3}$ National Childbirth Trust, NCT, 30 Euston Square, London NW1 2FB, UK. ${ }^{4}$ Division of Child Health, Obstetrics and Gynaecology, School of Medicine, Lenton, University of Nottingham, Nottingham NG7 2RD, UK.

Received: 27 August 2020 Accepted: 20 January 2021

Published online: 02 February 2021

\section{References}

1. Office of National Statistics. NHS Maternity Statistics England 2018-2019. https://digital.nhs.uk/data-and-information/publications/statistical/nhsmaternity-statistics/2018-19 Accessed 24th July 2020.

2. Untersheider J, McMenamin M, Cullinane F. Rising rates of caesarean deliveries at full cervical dilatation: a concerning trend. Eur J Obstet Gynaecol Reprod Biol. 2011;157(2):141-4.

3. Allen VM, O'Connell CM, Baskett TF. Maternal and perinatal morbidity of caesarean delivery at full cervical dilatation compared with caesarean delivery in the first stage of labour. BJOG. 2005;112(7):986-90.

4. Corry EMA, Ramphul M, Rowan AM, Sgurado R, Mahony RM, Keane DP. Exploring full cervical dilataion caesarean sections - a restrospective cohort study. Eur J Obstet Genecol Reprod Biol. 2018;224:188-91.

5. Waterfall H, Grivell RM, Dodd JM. Techniques for assisting difficult delivery at caesarean section. Cochrane Database Syst Rev. [Intervention Review] www.cochranelibrary.com/cdsr/doi/10.1002/14651858.CD004944. pub3/pdf/full.

6. Jeve YB, Navti OB, Konje JC. Comparison of techniques to deliver a deeply impacted fetal head at full dilatation: a systematic review and meta-analysis. Int J Obstet Gynaecol. 2015;123(3):337-45.

7. Medical Research Council. Developing and evaluating complex interventions. 2008. https://mrc.ukri.org/documents/pdf/complexinterventions-guidance/ Accessed 24 ${ }^{\text {th }}$ April, 2020.

8. Craig P, Dieppe P, Macintyre S, Michie S, Nazareth I, Petticrew M. Developing and evaluating complex interventions: the new Medical Research Council guidance. BMJ. 2008;337:a1655.

9. Braun V, Clarke V. Using thematic analysis in psychology. Qual Res Psychol. 2006:3:77-101.

10. Richards L. Using NVivo in qualitative research. London \& Los Angeles: Sage; 1999. ISBN 0-7619-6525-4

11. Githens PB, Glass CA, Sloan FA, Entman MD. Maternal Recall and Medical Records: An Examination of Events During Pregnancy, Childbirth, and Early Infancy 1993. Birth Issues Perinat Care. 1993;20(3):136-41.

12. Sekhon M, Cartwright M, Francis JJ. Acceptability of healthcare interventions: an overview of reviews and development of a theoretical framework. BMC Health Serv Res. 2017;17(1):88.

13. World Medical Association. Declaration of Helsinki - Ethical principles for medical research involving human subjects 2013. https://www.wma.net/ policies-post/wma-declaration-of-helsinki-ethical-principles-for-medicalresearch-involving-human-subjects/ Accessed $24^{\text {th }}$ April 2020.

14. Health Research Authority. UK Department of Health Policy Framework for Health and Social Care. https://www.hra.nhs.uk/planning-and-improvingresearch/policies-standards-legislation/uk-policy-framework-health-socialcare-research Accessed $24^{\text {th }}$ April, 2019.

15. Starcke K, Brand M. Decision making under stress: a selective review. Neurosci Biobehav Rev. 2012;36(4):1228-48.

16. Houghton G, Kingdon C, Dower M, Shakur-Still H, Alfirevic Z. What women think about consent to research at the time of an obstetric emergency: a 
qualitative study of the views of a cohort of world maternal Antifibrinolytic trial participants. BJOG. 2018;125:1744-53.

17. Lawton J, Hallowell N, Snowdon C, Norman JE, Carruthers K, Denison FC. Written versus verbal consent: a qualitative study of stakeholder views of consent procedures used at the time of recruitment into a peripartum trial conducted in an emergency setting. BMC Med Ethics. 2017;18(36):1-13.

18. Andersen $L B$, Melvaer $L B$, Videbech $P$, Lamont RF, Joergensen JS. Risk factors for developing post-traumatic stress disorder following childbirth: a systematic review. Acta Obstet Gynecol Scand. 2012;91(11): $1261-72$.

19. Ayers S. Delivery as a traumatic event: prevalence, risk factors, and treatment for postnatal posttraumatic stress disorder. Clin Obstet Gynecol. 2004;47(3):552-67.

\section{Publisher's Note}

Springer Nature remains neutral with regard to jurisdictional claims in published maps and institutional affiliations.

Ready to submit your research? Choose BMC and benefit from:

- fast, convenient online submission

- thorough peer review by experienced researchers in your field

- rapid publication on acceptance

- support for research data, including large and complex data types

- gold Open Access which fosters wider collaboration and increased citations

- maximum visibility for your research: over $100 \mathrm{M}$ website views per year

At BMC, research is always in progress.

Learn more biomedcentral.com/submissions 